\title{
DREAM Is Involved in the Genesis of Inflammation-Induced Prolabour Mediators in Human Myometrial and Amnion Cells
}

\author{
Priyanka Goradia, ${ }^{1}$ Ratana Lim $\left(\mathbb{D},{ }^{1,2}\right.$ and Martha Lappas $\mathbb{D}^{1,2}$ \\ ${ }^{1}$ Obstetrics, Nutrition and Endocrinology Group, Department of Obstetrics and Gynaecology, University of Melbourne, \\ Melbourne, VIC, Australia \\ ${ }^{2}$ Mercy Perinatal Research Centre, Mercy Hospital for Women, Heidelberg, VIC, Australia \\ Correspondence should be addressed to Martha Lappas; mlappas@unimelb.edu.au
}

Received 7 November 2017; Accepted 17 January 2018; Published 22 February 2018

Academic Editor: George J. Daskalakis

\begin{abstract}
Copyright (C) 2018 Priyanka Goradia et al. This is an open access article distributed under the Creative Commons Attribution License, which permits unrestricted use, distribution, and reproduction in any medium, provided the original work is properly cited.

Preterm birth is the primary cause of perinatal morbidity and mortality worldwide. Inflammation induces a cascade of events leading to preterm birth by activating nuclear factor $-\kappa \mathrm{B}(\mathrm{NF}-\kappa \mathrm{B})$. In nongestational tissues, downstream regulatory element antagonist modulator (DREAM) regulates NF- $\kappa$ B activity. Our aims were to analyse DREAM expression in myometrium and fetal membranes obtained at term and preterm and to determine the effect of DREAM inhibition on prolabour mediators in primary myometrial and amnion cells. DREAM mRNA expression was significantly higher in fetal membranes obtained after spontaneous labour compared to nonlabour and in amnion from women with histological preterm chorioamnionitis when compared to amnion from women without chorioamnionitis. In primary myometrial and amnion cells, the effect of DREAM silencing by siRNA was a significant decrease in the expression of proinflammatory cytokine IL-6, the chemokines IL-8 and MCP-1, the adhesion molecule ICAM-1, MMP-9 mRNA expression and activity, and NF- $\kappa$ B transcriptional activity when stimulated with the proinflammatory cytokine IL-1 $\beta$, the bacterial products fsl-1 or flagellin, or the viral dsRNA analogue poly(I:C). These data suggest that, in states of heightened inflammation, DREAM mRNA expression is increased and that, in myometrial and amnion cells, DREAM regulates proinflammatory and prolabour mediators which may be mediated via NF- $\kappa$ B.
\end{abstract}

\section{Introduction}

Preterm birth, defined as delivery prior to 37 weeks of gestation, affects approximately 15 million pregnancies annually and is the primary cause of perinatal morbidity and mortality worldwide [1]. Spontaneous preterm birth accounts for up to $70 \%$ of all cases [2]. Globally, more than one million preterm babies die each year, and those who survive have significantly higher rates of health complications, such as respiratory distress, jaundice, cerebral palsy, and cognitive impairments, compared to those born at term $[3,4]$. Intensive short- and long-term care for these babies poses a significant economic challenge, while the emotional toll borne by their families, also, is immense [5]. Despite clinical interventions and extensive research, preterm birth rates continue to rise. A more thorough understanding of the mechanisms of human parturition is essential to designing new and effective strategies for the prevention and management of preterm labour.

Healthy term labour is widely acknowledged to be a physiological, inflammatory state characterised by leukocytic infiltration of the myometrium, cervix, and fetal membranes $[6,7]$. The subsequent release of proinflammatory cytokines, such as interleukin- (IL-) $1 \beta$, facilitates the processes of parturition, with elevated levels found in myometrium, amnion, cervical tissue, and amniotic fluid in association with labour $[7,8]$. IL-1 $\beta$ can amplify production of cytokines and chemokines, including IL-8 and monocyte chemoattractant protein-1 (MCP-1), and upregulate the expression of cell adhesion molecules such as intercellular adhesion molecule1 (ICAM-1), which promotes further leukocyte recruitment [9]. They also induce cyclooxygenase-2 (COX-2) expression, resulting in uterotonic prostaglandin production $[10,11]$, and that of matrix metalloproteinase- (MMP-) 9, an extracellular 
matrix remodelling enzyme implicated in cervical ripening and membrane rupture [12]. Spontaneous preterm birth is thought to result from untimely and pathological activation of this pathway due to infection, haemorrhage, uterine distention, obesity, or stress, among others $[2,13]$. These disease processes share the feature of amplified local or systemic inflammation. Of these, infection has the greatest clinical significance [14] and initiates the aforementioned cascade of inflammatory events via toll-like receptor (TLR) activation by bacterial or viral products.

The nuclear factor-kappa B (NF- $\kappa \mathrm{B})$ signalling pathway is classically associated with inflammation and, in gestational tissues, is a critical regulator of prolabour mediators $[15,16]$. $\mathrm{NF}-\kappa \mathrm{B}$ is highly inducible by IL- $1 \beta$ and microbial products, while NF- $\kappa \mathrm{B}$ recognition elements are found within genes encoding IL- $1 \beta$, IL- 6 , IL- 8 , and TNF- $\alpha$, creating a positive feedback loop. Expression of the RelA subunit is significantly increased in myometrium and amnion in association with labour $[17,18]$. Furthermore, NF- $\kappa$ B inhibition has been shown to dampen expression of prolabour mediators in response to proinflammatory stimuli in myometrium, amnion, and placenta [19-21] and also delay time to delivery in mice [22]. Thus, controllable modulation of NF- $\kappa \mathrm{B}$ signalling may be of value in preventing spontaneous preterm birth.

Downstream regulatory element antagonist modulator (DREAM), also known as calsenilin and KChIP3, belongs to the neuronal calcium sensor family and has recently been shown to play a role in NF- $\kappa \mathrm{B}$ signalling [23-25]. It primarily exists in the cytosol, but nuclear and plasma membrane localisation have also been reported [26, 27]. Three isoforms are known to exist, with molecular weights of $29.1 \mathrm{kD}, 26.7 \mathrm{kD}$, and $26.3 \mathrm{kD}$. Initial identification of DREAM encompassed various biological processes, including senile plaque production in Alzheimer's disease, pain sensation, membrane excitability, and synaptic plasticity [2729]. DREAM-deficient mice consistently display attenuated responses to inflammatory pain models and have decreased levels of NF- $\kappa$ B-transcribed proinflammatory mediators in animal models of inflammatory lung and vascular injury $[24,25,30]$. Additionally, DREAM has been shown to bind to promoters of anti-inflammatory cytokines, suppressing their transcription [31]. Only one study has investigated the role of DREAM in pregnancy tissues. DREAM mRNA expression is upregulated in placentas from women with severe early onset preeclampsia [32], another adverse pregnancy outcome associated with inflammation.

Given the central role of inflammation and NF- $\kappa \mathrm{B}$ signalling in the processes of human labour and delivery, it was hypothesised that (i) human labour and infection would be associated with increased DREAM expression in human myometrium and fetal membranes and (ii) DREAM silencing would be associated with decreased expression and release of prolabour mediators in the presence of proinflammatory stimuli. Thus, the aims of this study were to (i) characterise the expression of DREAM in human myometrium and fetal membranes obtained from labouring and nonlabouring women at term and preterm with and without evidence of infection and (ii) determine the effect of DREAM silencing on prolabour mediators in human primary myometrial and amnion cells. The proinflammatory cytokine IL-1 $\beta$, the TLR2/6 ligand and bacterial product fibroblast-stimulating lipopeptide- (fsl-) 1, the TLR5 ligand and bacterial product flagellin, and the TLR3 ligand and viral dsRNA analogue polyinosinic:polycytidylic acid (poly(I:C)) were chosen as they have been shown to promote the expression of proinflammatory and prolabour mediators in human gestational tissues [21, 33, 34].

\section{Materials and Methods}

2.1. Ethics Statement. This study was approved by the Research Ethics Committee of Mercy Hospital for Women. Written, informed consent was obtained from all participating women.

2.2. Tissue Collection. Myometrium and fetal membranes were collected for two separate studies: expression studies and cell culture studies. All tissues were obtained from women who delivered healthy, singleton infants. Exclusion criteria were BMI > 30, abnormal antenatal glucose tolerance test results, any underlying medical conditions (for example, diabetes mellitus, macrovascular complications, polycystic ovarian syndrome, and preeclampsia), multiple pregnancies, and presence of fetal chromosomal abnormalities. Tissues were processed in the laboratory within $15 \mathrm{~min}$ of delivery.

2.2.1. Tissue Collection for Expression Studies. The full clinical characteristics of the patients used for the expression studies are described elsewhere [35].

Myometrium was obtained from women at term (37-41 weeks' gestation) undergoing (i) elective Caesarean section in the absence of labour and (ii) emergency Caesarean section during active labour ( $n=8$ patients per group). Indications for Caesarean section in the absence of labour were breech presentation and/or previous Caesarean section. Indications for Caesarean section in the presence of labour were placenta praevia, fetal distress, and failure to progress. Myometrial biopsies were obtained from the upper margin of the lower uterine segment incision during Caesarean section. No patients underwent induction or augmentation of labour. Tissue samples were snap frozen in liquid nitrogen and immediately stored at $-80^{\circ} \mathrm{C}$.

Fetal membranes were obtained from women (i) at term undergoing elective Caesarean section in the absence of labour and (ii) at term after spontaneous labour, spontaneous membrane rupture, and normal vaginal delivery $(n=9$ patients per group). Indications for Caesarean section were breech presentation and/or previous Caesarean section. No patients underwent induction or augmentation of labour. Tissue samples were snap frozen in liquid nitrogen and immediately stored at $-80^{\circ} \mathrm{C}$.

Fetal membranes were also obtained from women at preterm birth for two separate studies on preterm labour and preterm chorioamnionitis. For the preterm labour study, fetal membranes (amnion and choriodecidua) were obtained from women (i) undergoing Caesarean section in the absence of labour with intact membranes and (ii) after spontaneous 
labour and normal vaginal delivery $(n=9$ patients per group). For the chorioamnionitis study, only amnion was collected as the choriodecidual tissue was degraded. Amnion was collected from women (i) undergoing Caesarean section in the absence of labour and (ii) undergoing Caesarean section in the absence of labour with histologically confirmed acute chorioamnionitis ( $n=8$ patients per group). Indications for preterm delivery (in the absence of labour) were placenta praevia, placental abruption, antepartum haemorrhage, or rhesus isoimmunisation. All preterm placentas were subject to histopathological examination and fetal membranes were swabbed for microbiological culture studies. Chorioamnionitis was diagnosed pathologically according to standard criteria [36].

2.2.2. Tissue Collection for Cell Culture Studies. For the cell culture studies, fresh amnion and myometrium were obtained from women who delivered healthy, singleton infants at term (37-40 weeks' gestation) undergoing elective Caesarean section in the absence of labour. Primary amnion and myometrial cells were isolated and cultured as previously described [37, 38].

\subsection{DREAM siRNA Transfection in Primary Myometrial} and Amnion Cells. Primary myometrial and amnion cells were transfected with siRNA. Myometrial and amnion cells at approximately 50\% confluence were transfected using Lipofectamine 3000 according to manufacturer's guidelines (Life Technologies; Mulgrave, Victoria, Australia). DREAM siRNA (siDREAM) and negative control (siCONT) were obtained from Ambion (Thermo Fisher Scientific; Scoresby, VIC, Australia). Myometrial cells were transfected with $50 \mathrm{nM}$ siDREAM or $50 \mathrm{nM}$ siCONT in DMEM/F-12 for $48 \mathrm{~h}$ followed by treatment with or without $100 \mathrm{pg} / \mathrm{ml} \mathrm{IL-}$ $1 \beta, 250 \mathrm{ng} / \mathrm{ml}$ fsl- $1,1 \mu \mathrm{g} / \mathrm{ml}$ flagellin, or $5 \mu \mathrm{g} / \mathrm{ml}$ poly(I:C) for $24 \mathrm{~h}$. Amnion cells were transfected with $50 \mathrm{nM}$ siDREAM or $50 \mathrm{nM}$ siCONT in DMEM/F-12 for $48 \mathrm{~h}$ followed by treatment with or without $100 \mathrm{pg} / \mathrm{ml} \mathrm{IL}-1 \beta$ for $24 \mathrm{~h}$. After the final incubation, cells and media were collected and stored at $-80^{\circ} \mathrm{C}$ until assayed as detailed below. Cell viability was assessed by the 3-(4,5-dimethyl-2-thiazolyl)-2,5-diphenyl$2 \mathrm{H}$-tetrazolium bromide (MTT) proliferation assay as we have previously described [39]. The data is presented as fold change in expression relative to the expression level in the IL-1 $\beta$, flagellin-, and fsl-1- or poly(I:C)-stimulated siCONTtransfected cells, which was set at 1 . Each experiment was performed on amnion and myometrium obtained from six patients.

2.4. NF- $\kappa B$ RelA Luciferase Activity. Possible interactions between DREAM and NF- $\kappa$ B were determined using a luciferase assay, as previously described [40]. Primary myometrial cells, prepared as above, at $\sim 70 \%$ confluence were transfected with $0.75 \mathrm{ng}$ NF- $\kappa \mathrm{B}$ RelA reporter construct (Qiagen) using FuGENE HD transfection reagent (Promega, Alexandria, NSW, Australia). After $6 \mathrm{~h}$, cells were transfected with $50 \mathrm{nM}$ siDREAM or siCONT (as detailed above) for $48 \mathrm{~h}$. The medium was then replaced with DMEM/F12 containing $0.5 \%$ BSA with or without $100 \mathrm{pg} / \mathrm{ml} \mathrm{IL-1} \beta, 250 \mathrm{ng} / \mathrm{ml}$ fsl-1, $1 \mu \mathrm{g} / \mathrm{ml}$ flagellin, or $5 \mu \mathrm{g} / \mathrm{ml}$ poly(I:C), and the cells were incubated at $37^{\circ} \mathrm{C}$ for an additional $24 \mathrm{~h}$. Cells were harvested in lysis buffer and luminescence activity was measured using a luciferase reporter assay kit (Life Research, Scoresby, Victoria, Australia) and Renilla luciferase flash assay kit (Thermo Fisher Scientific, Scoresby, Victoria, Australia), as per the manufacturer's instructions. The ratio of firefly luciferase level to Renilla luciferase level was determined and results are expressed as a ratio of normalised luciferase activity. The experiments were performed on myometrium obtained from six patients.

2.5. RNA Extraction and qRT-PCR. RNA extraction and qRTPCR were performed as previously described [40]. Total RNA was extracted from tissues and cells using TRIsure reagent, as per the manufacturer's instructions (Bioline, Alexandria, NSW, Australia). RNA concentration and purity were measured using a NanoDrop ND1000 Spectrophotometer. RNA quality was determined via the $A_{260}: A_{280}$ ratio. RNA was converted to cDNA using the high-capacity cDNA reverse transcription kit (Thermo Fisher Scientific; Scoresby, Vic, Australia) according to the manufacturer's instructions. The RT-PCR was performed using the CFX384 Real-Time PCR detection system (Bio-Rad Laboratories; Gladesville, NSW, Australia) using $100 \mathrm{nM}$ of predesigned and validated QuantiTect primers (primer sequences not available) (Qiagen; Chadstone Centre, Vic, Australia). Average gene Ct values were normalised to the average YWHAZ and succinate dehydrogenase (SDHA) Ct values of the same cDNA sample. Fold differences were determined using the comparative $\mathrm{Ct}$ method.

2.6. Enzyme Immunoassays. IL-6 and IL-8 release were assessed using the CytoSet ${ }^{\mathrm{TM}}$ sandwich ELISA, as instructed (Life Technologies). MCP-1 and ICAM-1 release were assessed by sandwich ELISA from R\&D Systems (Minneapolis, MN, USA), as instructed. The interassay and intra-assay coefficients of variation for all assays were less than $10 \%$.

2.7. Gelatin Zymography. MMP-9 activity was assessed by gelatin zymography on conditioned media collected from primary amnion cells, as previously described [34]. Briefly, proteolytic activity was visualised as clear zones of lysis on a blue background of undigested gelatin. Gels were scanned and inverted using the ChemiDoc XRS system (Bio-Rad Laboratories), and densitometry was performed using the Quantity One Image analysis software (Bio-Rad Laboratories).

2.8. Statistical Analysis. Statistical analysis was performed using GraphPad Prism (GraphPad Software, La Jolla, CA). For two sample comparisons, an unpaired Student's $t$-test was used to assess statistical significance between normally distributed data; otherwise, the nonparametric Mann-Whitney $U$ was used. For all other comparisons, the homogeneity of data was assessed by Bartlett's test, and, when significant, data were logarithmically transformed before analysis by a repeated measures one-way ANOVA (with LSD post hoc testing to discriminate among the means). Statistical significance 


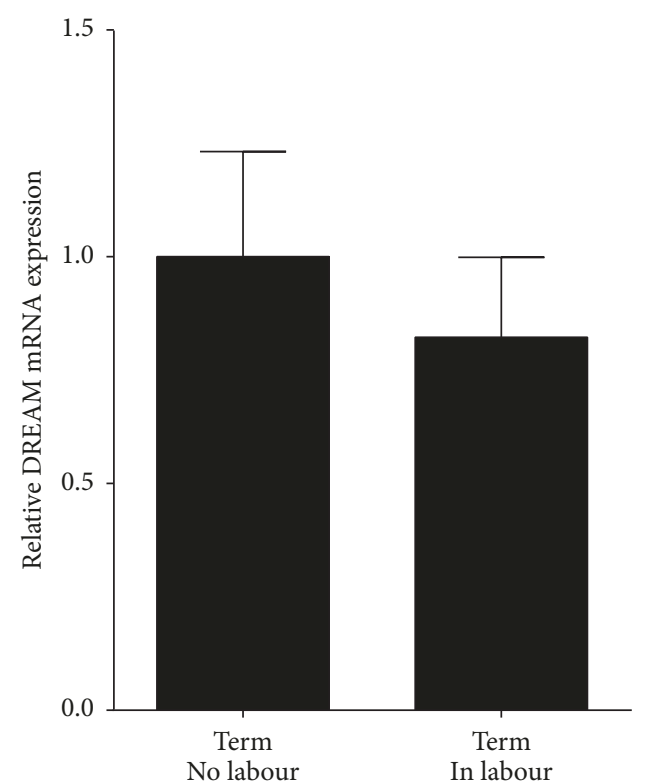

(a)

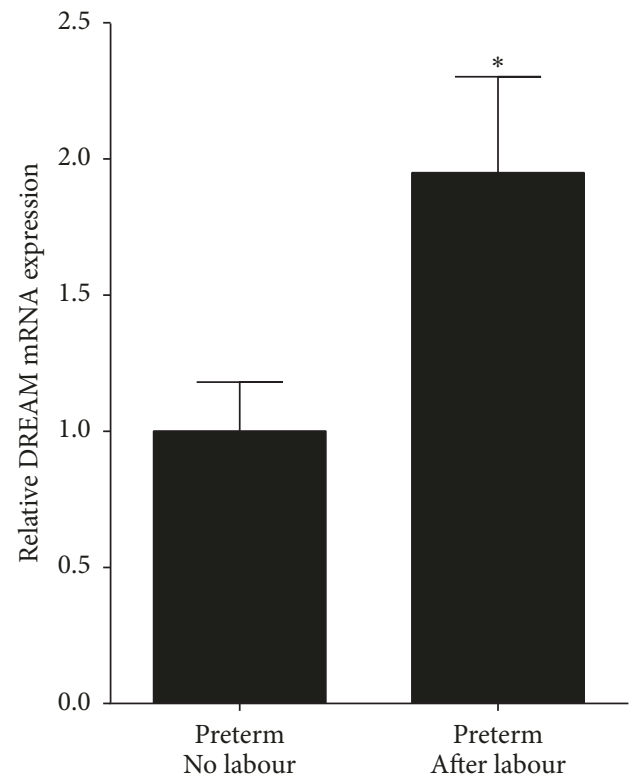

(c)

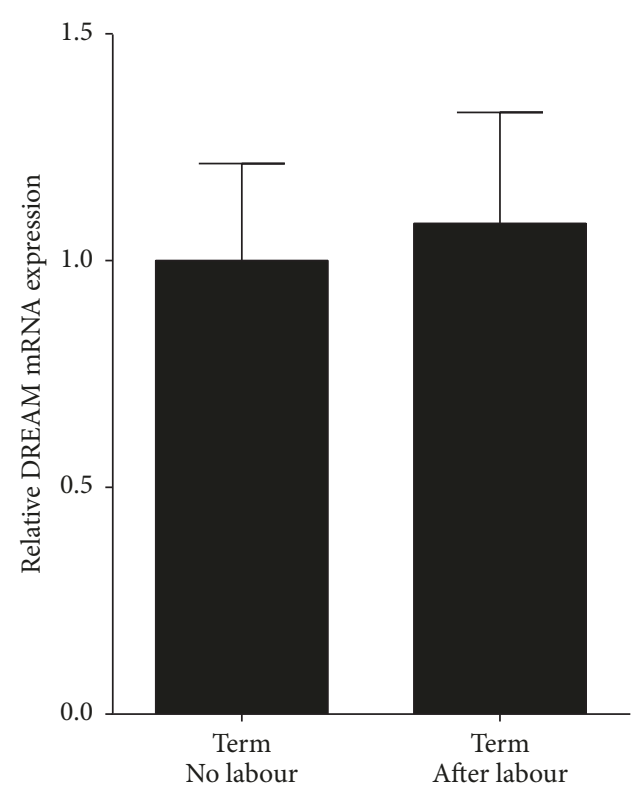

(b)

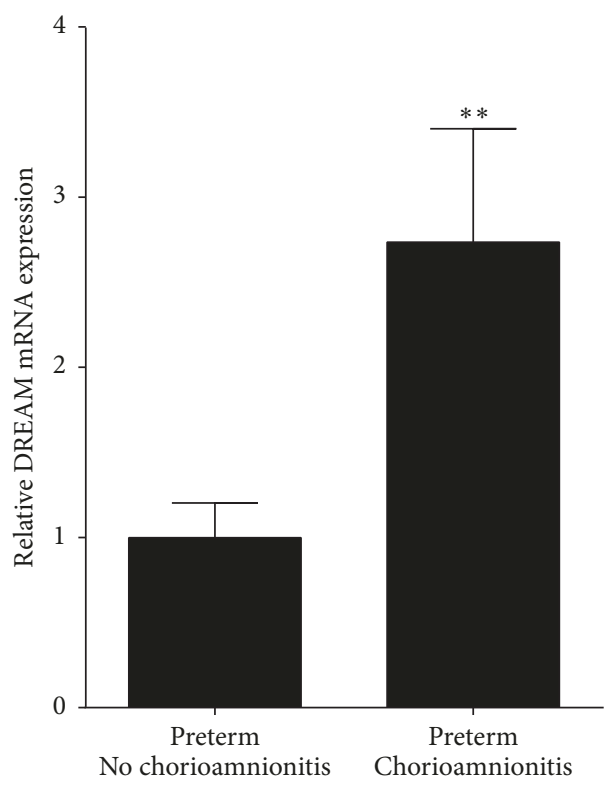

(d)

FIGURE 1: DREAM expression in human myometrium and fetal membranes. (a) Human myometrium was obtained from nonlabouring and labouring women at term Caesarean section ( $n=8$ patients per group). (b) Fetal membranes were obtained from women not in labour at term Caesarean section and women after term spontaneous labour onset and delivery ( $n=9$ patients per group). (c) Fetal membranes were obtained from women not in labour at preterm Caesarean section and women after preterm spontaneous labour onset and delivery $(n=9$ patients per group). (d) Amnion was obtained from women at preterm Caesarean section with or without histological chorioamnionitis ( $n=8$ patients per group). DREAM mRNA expression was analysed by qRT-PCR. All data are displayed as mean \pm SEM. ${ }^{*} p \leq 0.05$ versus preterm no labour (Student's $t$-test); ${ }^{* *} p \leq 0.05$ versus preterm no chorioamnionitis (Student's $t$-test).

was ascribed to a $p$ value $\leq 0.05$. Data is expressed as mean \pm SEM.

\section{Results}

3.1. Effect of Term and Preterm Labour and Infection on DREAM Expression in Human Myometrium and Fetal Membranes. We first characterised the expression of DREAM in myometrium and fetal membranes from nonlabouring and labouring women. DREAM mRNA expression was not different in myometrium and fetal membranes obtained from labouring and nonlabouring women at term (Figures 1(a) and $1(\mathrm{~b}))$. On the other hand, in fetal membranes obtained from women at preterm, DREAM mRNA expression was significantly higher in the labouring group compared to the nonlabouring group (Figure 1(c)). Furthermore, at preterm, 


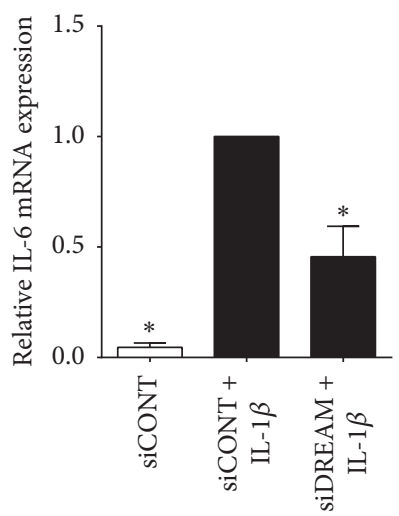

(a)

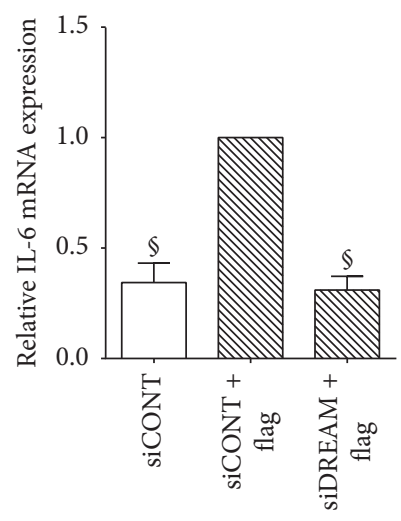

(e)

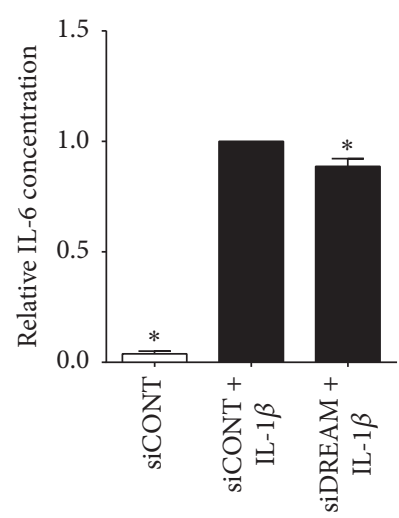

(b)

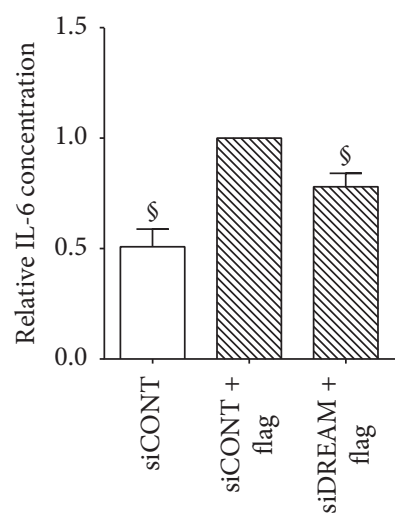

(f)

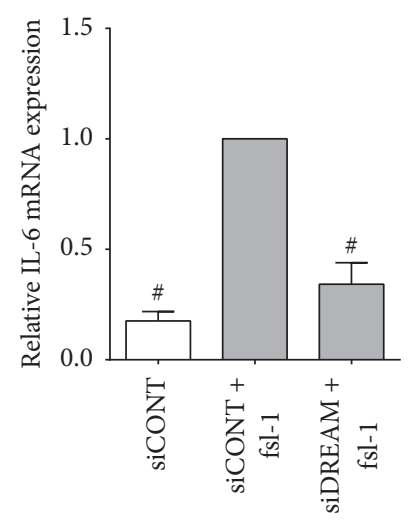

(c)

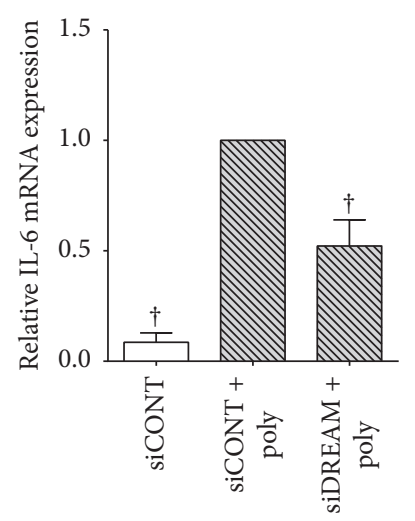

(g)

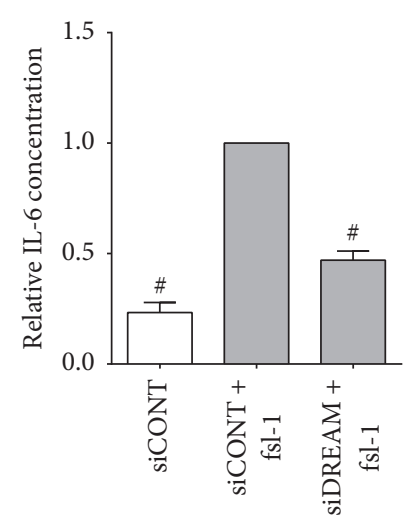

(d)

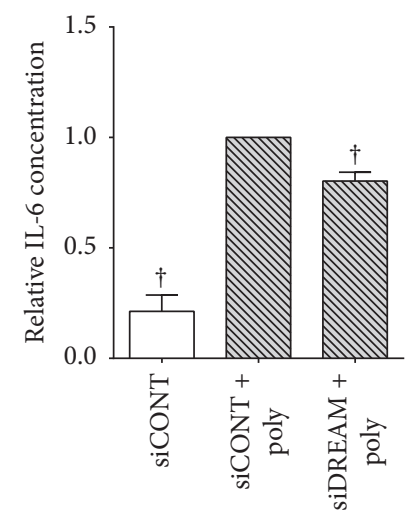

(h)

FIGURE 2: Effect of siDREAM on the proinflammatory cytokine IL-6 in primary myometrial cells. Primary myometrial cells were transfected with $50 \mathrm{nM}$ siCONT or $50 \mathrm{nM}$ siDREAM for $48 \mathrm{~h}$ and then treated with (a, b) $100 \mathrm{pg} / \mathrm{mL} \mathrm{IL-1} \beta$, (c, d) $250 \mathrm{ng} / \mathrm{ml} \mathrm{fsl}-1$, (e, f) $1 \mu \mathrm{g} / \mathrm{ml}$ flagellin, or (g, h) $5 \mu \mathrm{g} / \mathrm{ml}$ poly(I:C) for an additional $24 \mathrm{~h}$ (patients). (a, c, e, g) IL-6 mRNA expression was analysed by qRT-PCR. (b, d, f, h) The incubation media was assayed for concentration of IL- 6 by ELISA. For all data, fold change was calculated relative to IL- $1 \beta-$, fsl-1, and flagellin- or poly(I:C)-stimulated siCONT-transfected cells. Data are displayed as mean \pm SEM. ${ }^{*} p \leq 0.05$ versus IL-1 $\beta$-stimulated siCONT-transfected cells; ${ }^{\#} p \leq 0.05$ versus fsl-1-stimulated siCONT-transfected cells; ${ }^{\circledR} p \leq 0.05$ versus flagellin-stimulated siCONT-transfected cells; ${ }^{\dagger} p \leq 0.05$ versus poly(I:C)-stimulated siCONT-transfected cells (one-way ANOVA).

DREAM mRNA expression was also significantly higher in amnion obtained from women with histologically confirmed chorioamnionitis compared to those without histologically confirmed chorioamnionitis (Figure $1(\mathrm{~d})$ ). Several attempts to quantify DREAM protein with commercially available antibodies were unsuccessful.

\subsection{Effect of siDREAM on Proinflammatory Cytokines,} Chemokines, and Adhesion Molecules in Primary Myometrial and Amnion Cells. Functional siRNA studies were performed to determine the role of DREAM in the regulation of prolabour mediators. For these studies, we used primary cells isolated from human myometrium or amnion and treated them with the proinflammatory cytokine IL- $1 \beta$, the bacterial products fsl-1 or flagellin, and the viral dsRNA analogue poly(I:C) to induce inflammation associated with preterm labour. Following siRNA transfection, primary myometrial cells were treated with IL-1 $\beta$, fsl-1, flagellin, and poly(I:C). Amnion cells were treated with IL- $1 \beta$ only. Efficacy of transfection was assessed by qRT-PCR. As compared to siCONTtransfected myometrial and amnion cells, siDREAM transfection resulted in a decrease in DREAM mRNA expression by approximately 75\%. A MTT cell viability assay showed no difference in absorbance between siCONTand siDREAM-transfected myometrial $(0.63 \pm 0.34$ versus $0.66 \pm 0.27)$ and amnion $(1.49 \pm 0.15$ versus $1.45 \pm 0.15)$ cells.

The effect of siDREAM on proinflammatory cytokines, chemokines, and adhesion molecules is depicted in Figures 2-4 for myometrial cells and Figure 5 for amnion cells. In siCONT-transfected myometrial cells, treatment with IL-1 $\beta$, fsl-1, flagellin, and poly(I:C) significantly increased expression of IL-6 (Figure 2), IL-8, and MCP-1 (Figure 3). In siDREAM transfected cells, there was a significant attenuation of IL-6, IL-8, and MCP-1 mRNA expression and secretion when stimulated with all treatments. There was also a significant decrease in fsl-1, flagellin, and poly(I:C)-induced ICAM-1 mRNA expression and secretion in siDREAM transfected cells (Figure 4). There was a significant decrease in IL- $1 \beta$-induced ICAM- 1 mRNA expression, but no effect on secretion of sICAM-1 in siDREAM transfected cells (Figure 4). Similar results were obtained in amnion cells, where siDREAM transfected cells displayed an attenuation 


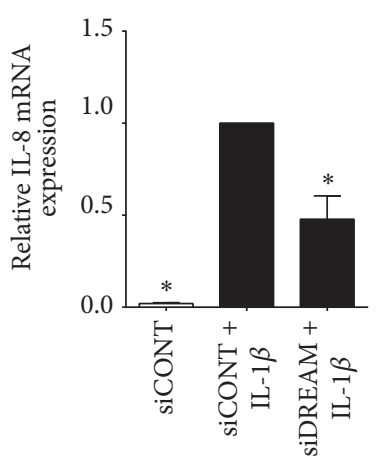

(a)

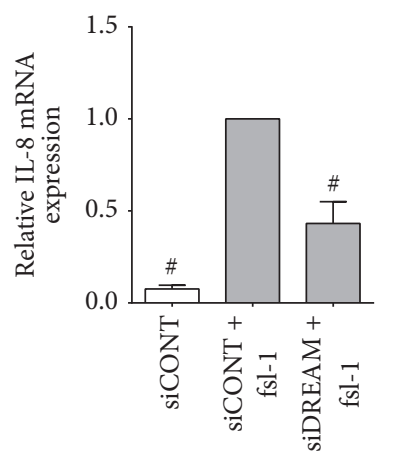

(e)

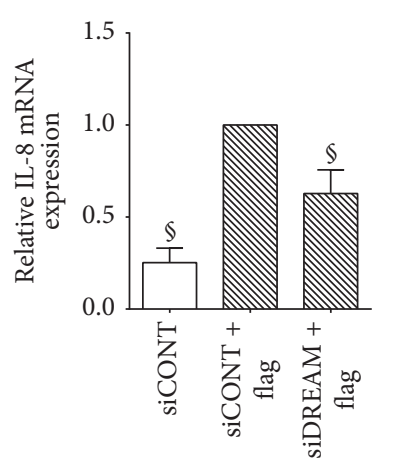

(i)

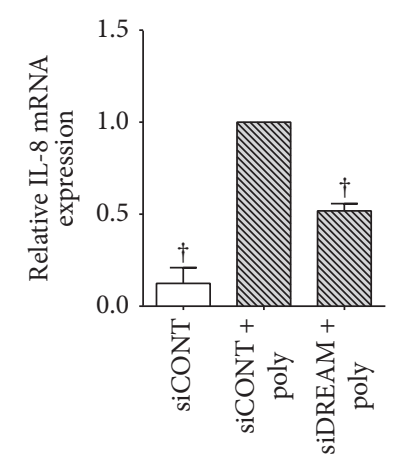

(m)

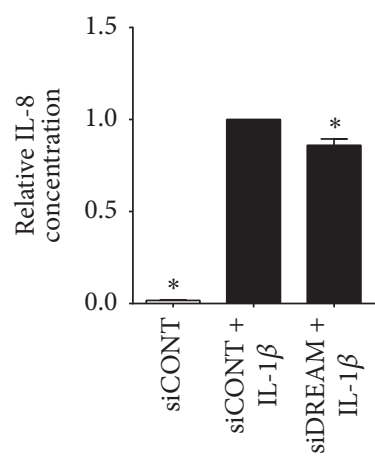

(b)

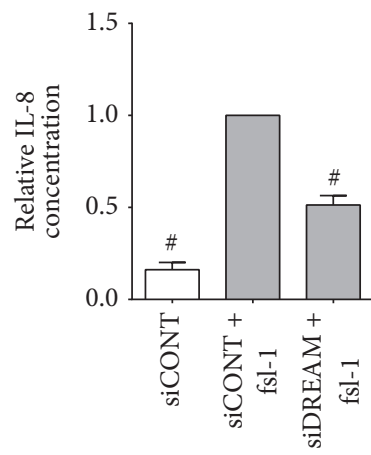

(f)

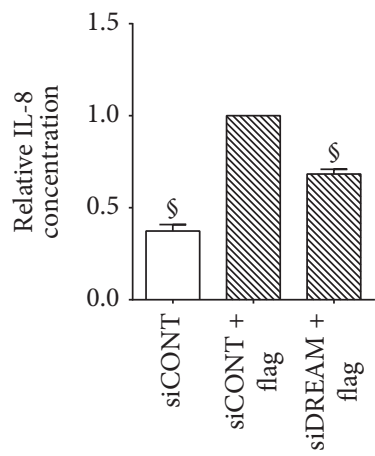

(j)

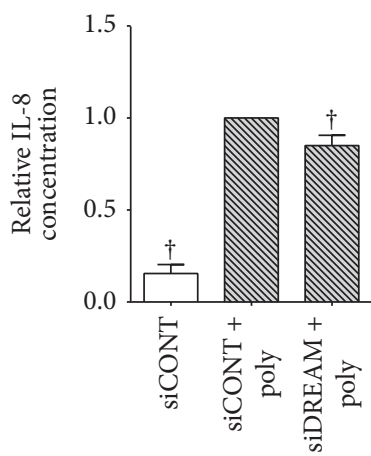

(n)

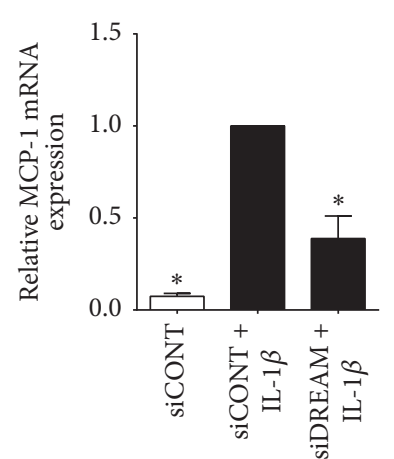

(c)

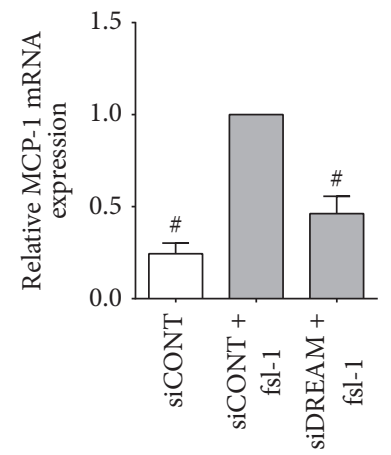

(g)

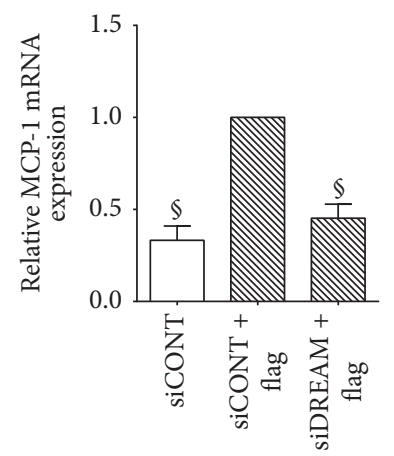

(k)

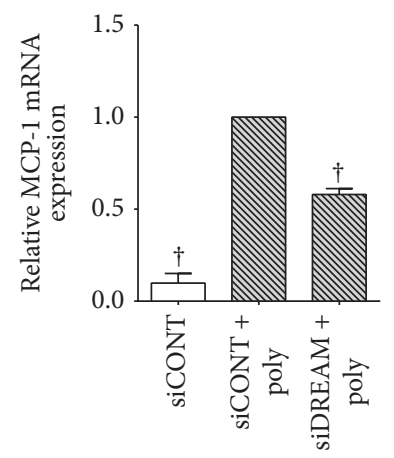

(o)

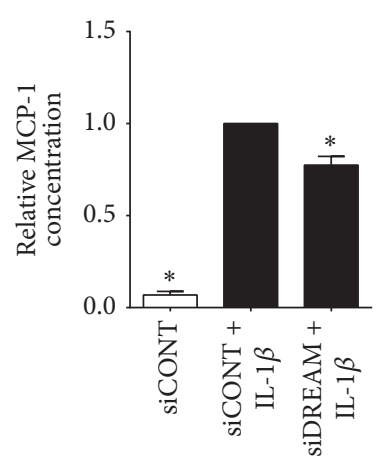

(d)

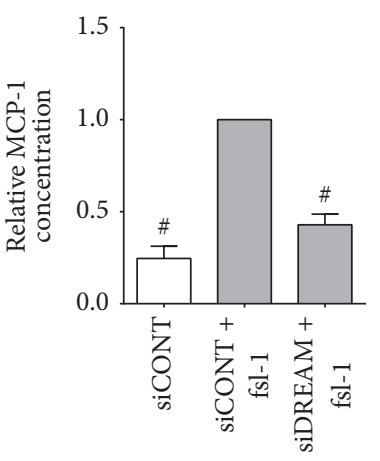

(h)

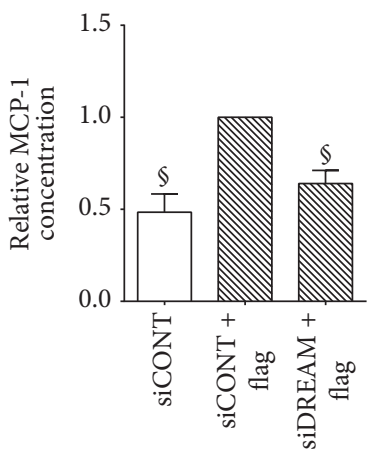

(1)

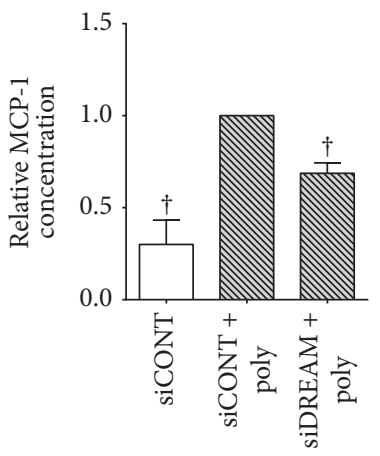

(p)

FIGURE 3: Effect of siDREAM on chemokines in primary myometrial cells. Primary myometrial cells were transfected with $50 \mathrm{nM}$ siCONT or $50 \mathrm{nM}$ siDREAM for $48 \mathrm{~h}$ and then treated with (a-d) $100 \mathrm{pg} / \mathrm{mL} \mathrm{IL-1 \beta}$, (e-h) $250 \mathrm{ng} / \mathrm{ml}$ fsl-1, (i-l) $1 \mu \mathrm{g} / \mathrm{ml} \mathrm{flagellin,} \mathrm{or} \mathrm{(m-p)} 5 \mu \mathrm{g} / \mathrm{ml}$ poly(I:C) for an additional $24 \mathrm{~h}$ ( $n=6$ patients). (a, c, e, g, i, k, m, o) IL-8 and MCP-1 mRNA expression were analysed by qRT-PCR. (b, $\mathrm{d}, \mathrm{f}, \mathrm{h}, \mathrm{j}, \mathrm{l}, \mathrm{n}, \mathrm{p})$ The incubation media was assayed for concentration of IL-8 and MCP-1 by ELISA. For all data, fold change was calculated relative to IL-1 $\beta$-, fsl-1, and flagellin- or poly(I:C)-stimulated siCONT-transfected cells. Data are displayed as mean \pm SEM. ${ }^{*} p \leq 0.05$ versus IL-1 $\beta$-stimulated siCONT-transfected cells; ${ }^{*} p \leq 0.05$ versus fsl-1-stimulated siCONT-transfected cells; ${ }^{\S} p \leq 0.05$ versus flagellin-stimulated siCONT-transfected cells; ${ }^{\dagger} p \leq 0.05$ versus poly(I:C)-stimulated siCONT-transfected cells (one-way ANOVA). 


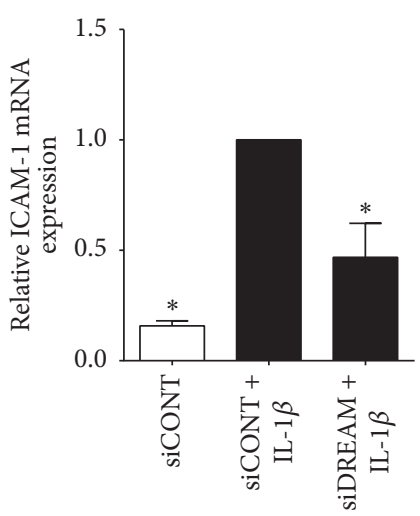

(a)

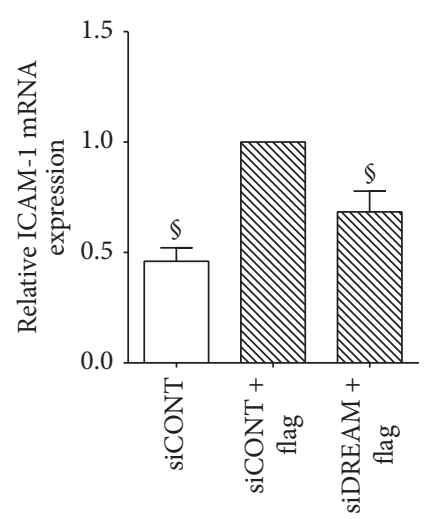

(e)

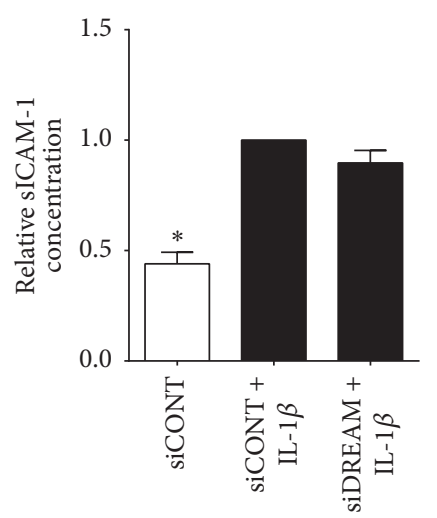

(b)

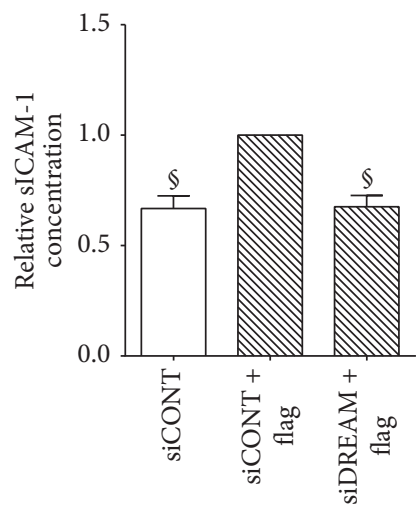

(f)

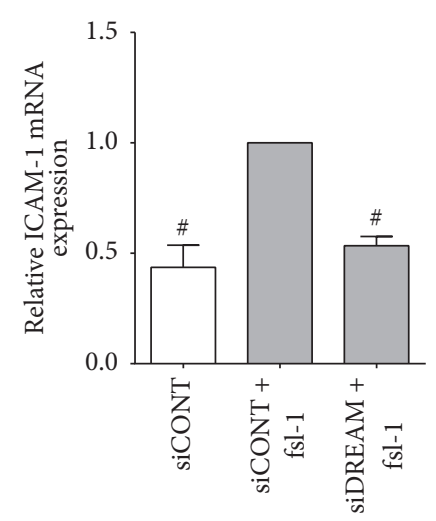

(c)

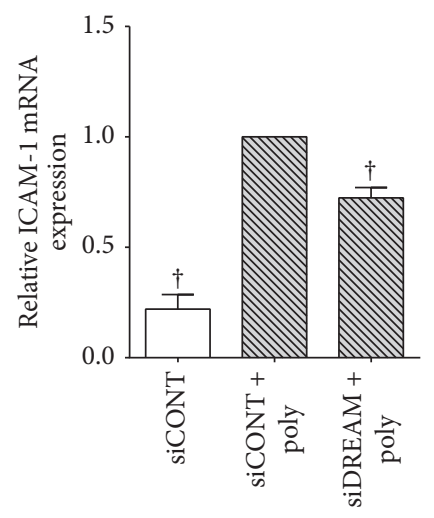

(g)

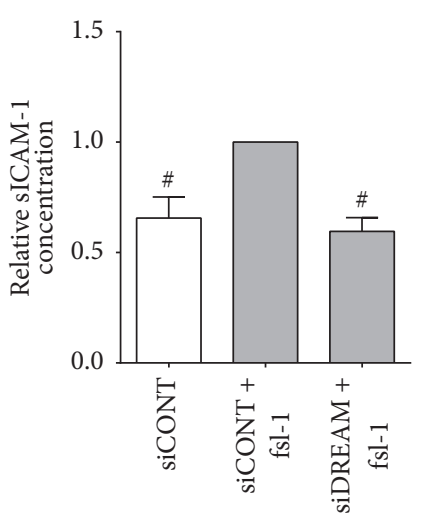

(d)

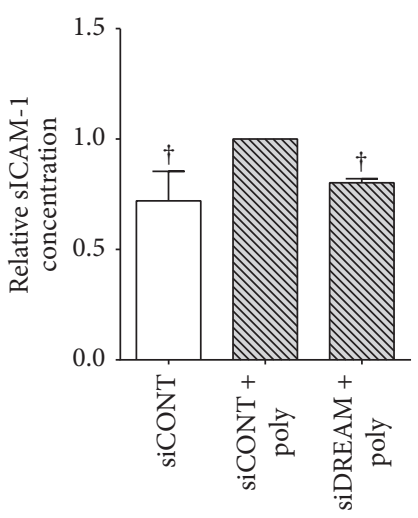

(h)

FIGURE 4: Effect of siDREAM on the adhesion molecule ICAM-1 in primary myometrial cells. Primary myometrial cells were transfected with $50 \mathrm{nM}$ siCONT or $50 \mathrm{nM}$ siDREAM for $48 \mathrm{~h}$ and then treated with (a, b) $100 \mathrm{pg} / \mathrm{mL} \mathrm{IL}-1 \beta$, (c, d) $250 \mathrm{ng} / \mathrm{ml}$ fsl-1, (e, f) $1 \mu \mathrm{g} / \mathrm{ml}$ flagellin, or (g, h) $5 \mu \mathrm{g} / \mathrm{ml}$ poly(I:C) for an additional $24 \mathrm{~h}$ ( $n=6$ patients). (a, c, e, g) ICAM-1 mRNA expression was analysed by qRT-PCR. (b, d, f, h) The incubation media was assayed for concentration of ICAM-1 by ELISA. For all data, fold change was calculated relative to IL-1 $\beta$-, fsl-1, and flagellin- or poly(I:C)-stimulated siCONT-transfected cells. Data are displayed as mean \pm SEM. * $p \leq 0.05$ versus IL- $1 \beta$-stimulated siCONTtransfected cells; ${ }^{\#} p \leq 0.05$ versus fsl-1-stimulated siCONT-transfected cells; ${ }^{\circledR} p \leq 0.05$ versus flagellin-stimulated siCONT-transfected cells; ${ }^{\dagger} p \leq 0.05$ versus poly(I:C)-stimulated siCONT-transfected cells (one-way ANOVA).

of IL- $1 \beta$-induced IL-6, IL-8, MCP-1, and ICAM-1 mRNA expression and secretion (Figure 5).

3.3. Effect of siDREAM on MMP-9 in Primary Amnion Cells. We also assessed the effect of siDREAM on the expression of the ECM degrading enzyme MMP-9 in primary amnion cells. As expected, IL-1 $\beta$ increased MMP-9 mRNA expression and secretory pro-MMP-9 levels in siCONT-transfected amnion cells (Figure 6). The effect of siDREAM was a significant suppression of IL-1 $\beta$-induced MMP-9 mRNA expression and pro-MMP-9 production.

3.4. Effect of siDREAM on NF- $\kappa B$ RelA Transcriptional Activity. Finally, we determined if the effects of siDREAM on prolabour mediators may be elicited through NF- $\kappa \mathrm{B}$; Figure 7 demonstrates the effect of siDREAM on NF- $\kappa$ B RelA transcriptional activity. In siCONT-transfected cells, NF- $\kappa$ B RelA transcriptional activity was significantly augmented by IL- $1 \beta$, fsl-1, flagellin, and poly(I:C) treatment. A significant reduction in IL-1 $\beta$-, fsl-1-, and flagellin- and poly(I:C)induced NF- $\kappa$ B RelA transcriptional activity was observed in siDREAM transfected cells.

\section{Discussion}

A greater understanding of the mechanisms of human parturition is necessary to design new and effective strategies for the prevention of preterm labour. Here, DREAM is identified as a novel therapeutic target. This study is the first to investigate expression and function of DREAM in human myometrium and fetal membranes. While DREAM expression is not altered by labour at term, its expression is significantly increased in fetal membranes after preterm labour and in amnion with histological preterm chorioamnionitis when compared to amnion without histological preterm chorioamnionitis. Functional studies in primary myometrial and amnion cells revealed that DREAM is involved in the production of proinflammatory and prolabour mediators induced by IL-1 $\beta$, fsl-1, flagellin, and poly(I:C). Additionally, 


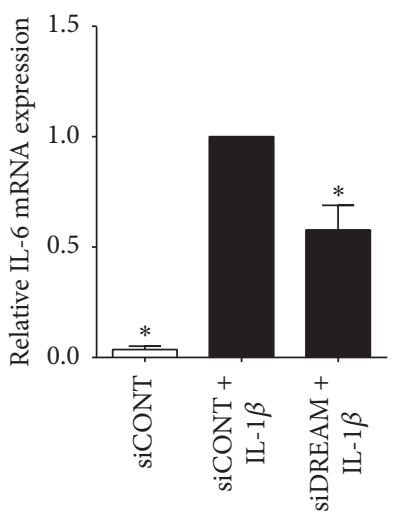

(a)

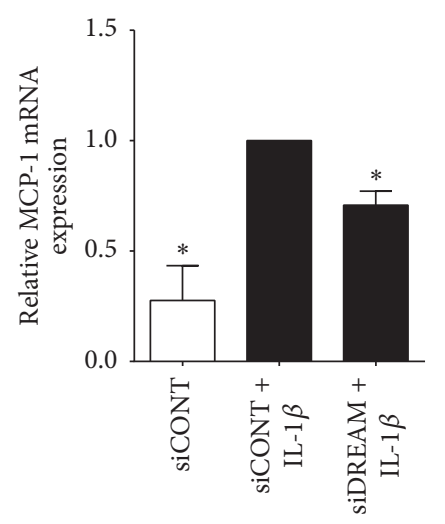

(e)

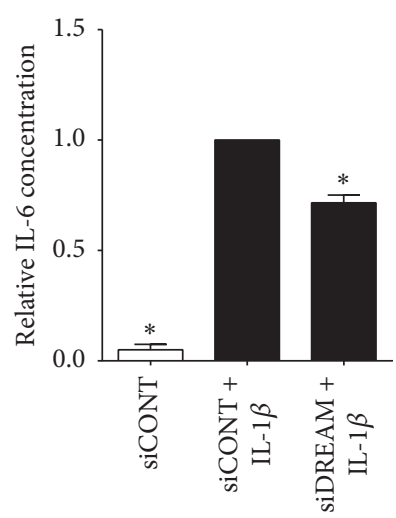

(b)

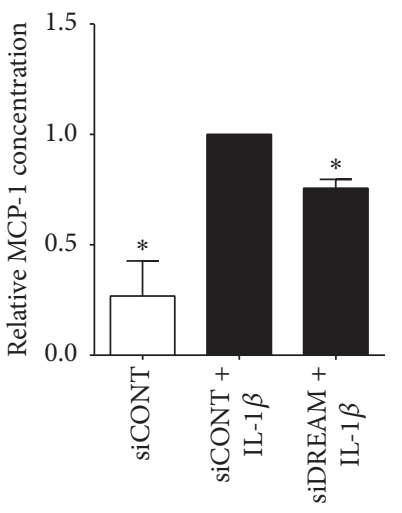

(f)

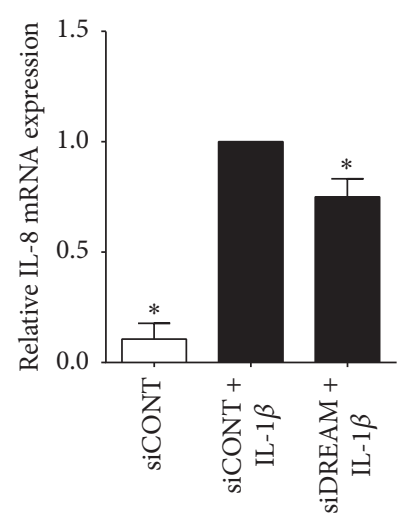

(c)

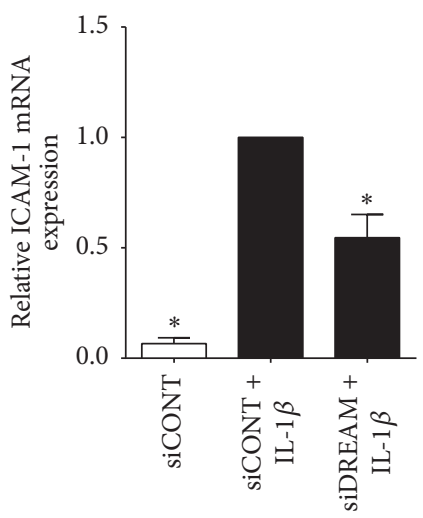

(g)

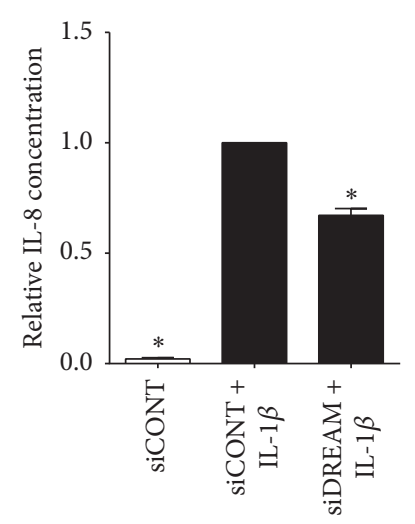

(d)

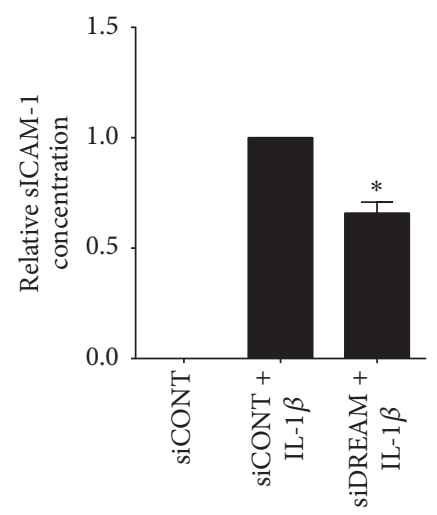

(h)

FIGURE 5: Effect of siDREAM on proinflammatory cytokines, chemokines, and adhesion molecules in primary amnion cells. Primary amnion cells were transfected with $50 \mathrm{nM}$ siCONT or $50 \mathrm{nM}$ siDREAM for $48 \mathrm{~h}$ and then treated with $100 \mathrm{pg} / \mathrm{mL}$ IL- $1 \beta$ for an additional $24 \mathrm{~h}$ ( $n=6$ patients). (a, c, e, g) IL-6, IL-8, MCP-1, and ICAM-1 mRNA expression were analysed by qRT-PCR. (b, d, f, h) The incubation media was assayed for concentration of IL-6, IL-8, MCP-1, and sICAM-1 by ELISA. For all data, fold change was calculated relative to IL$1 \beta$-stimulated siCONT-transfected cells. Data are displayed as mean \pm SEM. ${ }^{*} p \leq 0.05$ versus IL- $1 \beta$-stimulated siCONT-transfected cells (one-way ANOVA).

NF- $\kappa$ B RelA transcriptional activity was significantly reduced in siDREAM transfected myometrial cells, suggesting that DREAM may regulate prolabour mediators via NF- $\kappa \mathrm{B}$ signalling.

Increased DREAM expression is implicated in both physiological and pathological inflammatory states, including pain sensation (a hallmark of inflammation), Alzheimer's disease, and preeclampsia [27, 29, 32]. Inflammation is a common feature of human labour, with increased production of proinflammatory cytokines (such as IL-1 $\beta$ ) by leukocytes infiltrating the myometrium, cervix, and fetal membranes $[6,7]$. In this study, DREAM expression was similar between myometrium and fetal membranes obtained from nonlabouring and labouring women at term. On the other hand, at preterm, DREAM expression was significantly increased in fetal membranes from labouring women compared to nonlabouring women. This suggests that DREAM is not involved in the processes of healthy labour at term but is involved in the pathological activation of labour at preterm. Preterm labour is associated with increased inflammation in myometrium, fetal membranes, and amniotic fluid in the absence of infection, but also in an exaggerated manner in cases of infection [13]. We found that DREAM mRNA expression was significantly increased in preterm amnion with histological chorioamnionitis compared to amnion without histological chorioamnionitis. The fact that DREAM mRNA expression was increased in amnion with chorioamnionitis suggests that this increase may be caused by infection. Further studies are required to determine the role of proinflammatory and infectious stimuli in regulating DREAM expression. While it would be of great benefit to determine the expression of DREAM in myometrium from preterm deliveries with or without infection, obtaining such samples is extremely difficult. Notably, we only assessed DREAM mRNA expression; protein data are needed to verify these findings. Notwithstanding these limitations, the data collectively suggest that DREAM upregulation is more prevalent in states of heightened inflammation. Functional studies were then performed to determine whether DREAM regulates proinflammatory and prolabour mediators. For these studies, the proinflammatory cytokine IL- $1 \beta$, two bacterial products (fsl-1 and flagellin), and one viral product (poly(I:C)) were 


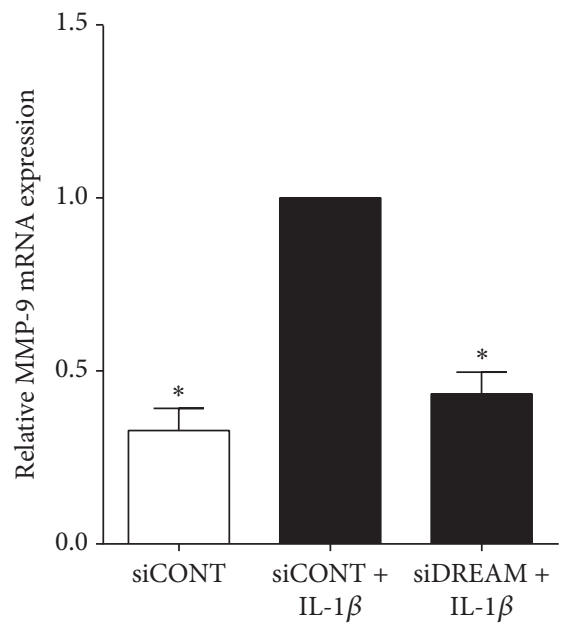

(a)

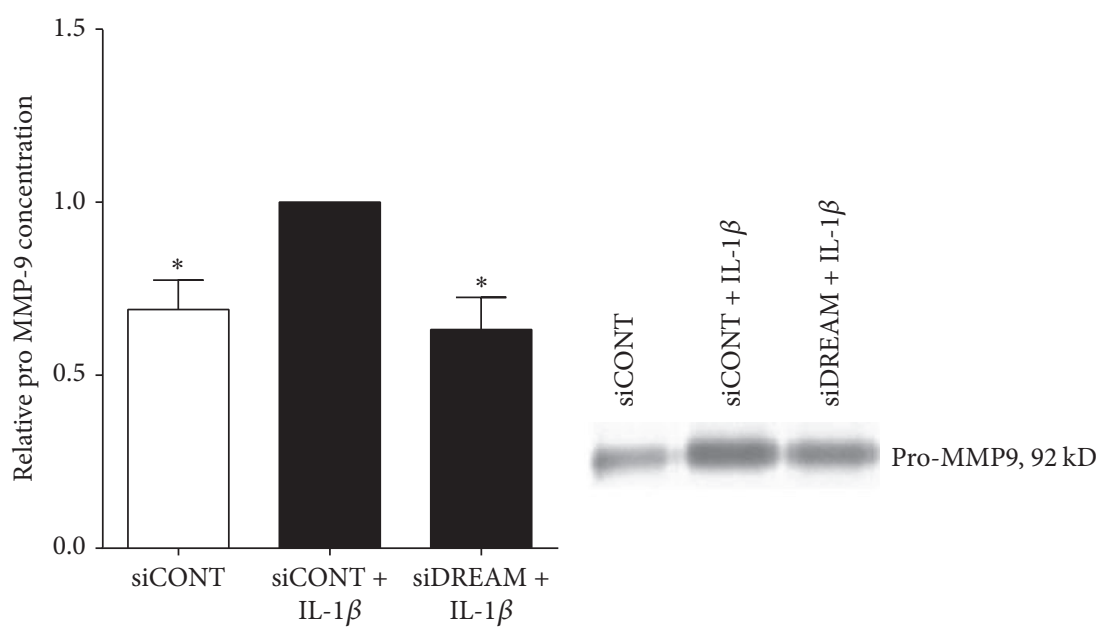

(b)

FIGURE 6: Effect of siDREAM on the ECM degrading enzyme MMP-9 in primary amnion cells. Primary amnion cells were transfected with $50 \mathrm{nM}$ siCONT or siDREAM for $48 \mathrm{~h}$ and then treated with $100 \mathrm{pg} / \mathrm{mL}$ IL- $1 \beta$ for an additional $24 \mathrm{~h}(n=6$ patients). (a) MMP-9 mRNA expression was analysed by qRT-PCR. (b) The incubation media was assessed for pro-MMP-9 proteolytic activity using gelatin zymography. Representative zymogram from one patient is shown. For all data, fold change was calculated relative to IL- $1 \beta$-stimulated siCONT-transfected cells. Data are displayed as mean \pm SEM. ${ }^{*} p \leq 0.05$ versus IL- $\beta$-stimulated siCONT-transfected cells (one-way ANOVA).

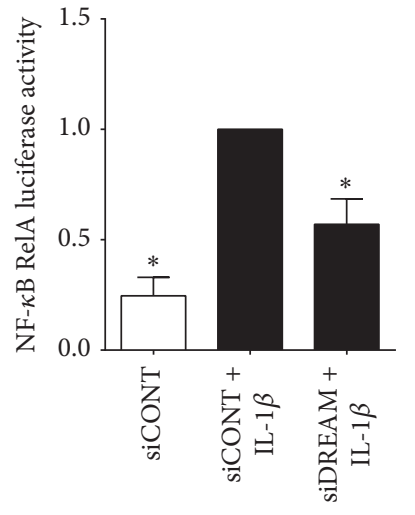

(a)

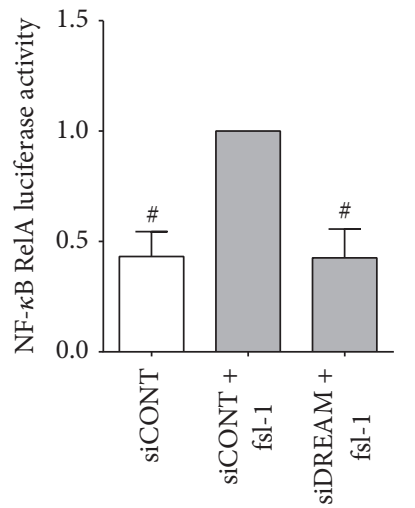

(b)

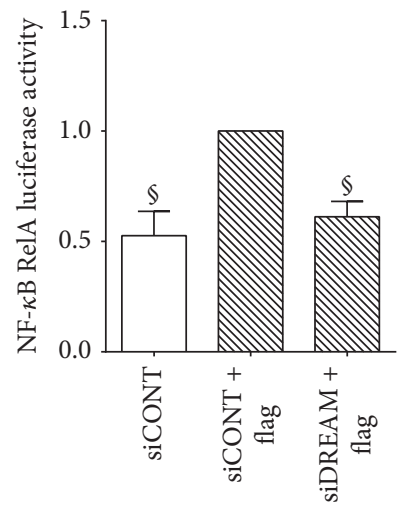

(c)

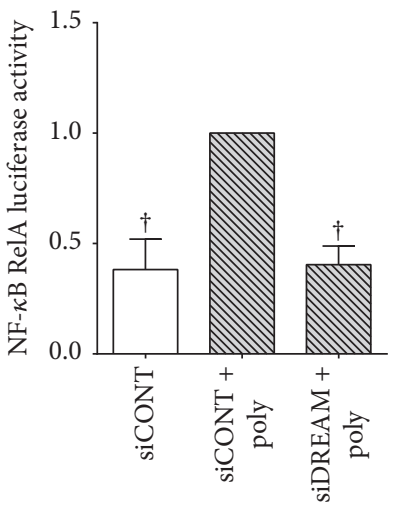

(d)

FiguRE 7: Effect of siDREAM on NF- $\kappa$ B RelA transcriptional activity. Primary myometrial cells were transfected with $300 \mathrm{ng} / \mathrm{ml}$ NF- $\kappa \mathrm{B}$ RelA reporter construct for $6 \mathrm{~h}$, transfected with $50 \mathrm{nM}$ siCONT or siDREAM for $48 \mathrm{~h}$, and then treated with (a) $100 \mathrm{pg} / \mathrm{ml} \mathrm{IL-1} \beta$, (b) $250 \mathrm{ng} / \mathrm{ml}$ fsl-1, (c) $1 \mu \mathrm{g} / \mathrm{ml}$ flagellin, or (d) $5 \mu \mathrm{g} / \mathrm{ml}$ poly(I:C) for an additional $24 \mathrm{~h}(n=5-6$ patients). Promoter activity was normalised to Renilla expression. Fold change was calculated relative to IL-1 $\beta$-, fsl-1, and flagellin- or poly(I:C)-stimulated siCONT-transfected cells. Data are displayed as mean \pm SEM. ${ }^{*} p \leq 0.05$ versus IL- $1 \beta$-stimulated siCONT-transfected cells; ${ }^{\#} p \leq 0.05$ versus fsl-1-stimulated siCONT-transfected cells; ${ }^{\S} p \leq 0.05$ versus flagellin-stimulated siCONT-transfected cells; ${ }^{\dagger} p \leq 0.05$ versus poly(I:C)-stimulated siCONT-transfected cells (one-way ANOVA).

used to mimic inflammation associated with preterm labour $[33,41]$.

$\mathrm{IL}-1 \beta$ is a proinflammatory cytokine released from infiltrating leukocytes in intrauterine tissues [7] that are central to the terminal pathways of human labour and delivery. Elevated IL-1 $\beta$ expression is found in the human myometrium, amnion, amniotic fluid, and cervix in association with term and preterm labour $[6,7,42]$, while in intra-amniotic administration of IL- $1 \beta$ it induces preterm delivery in mice and rhesus monkeys $[43,44]$. In intrauterine tissues, IL- $1 \beta$ has been shown to induce expression of chemokines, adhesion molecules, MMPs, and contractions associated proteins
[10, 45-48]. In this study, siDREAM knockdown in primary myometrial and amnion cells was associated with significant decrease in IL- $1 \beta$-induced expression and secretion of the proinflammatory cytokine IL- 6 , the chemokines IL- 8 and MCP-1, and the adhesion molecule ICAM-1. Collectively, however, the results of this study indicate that DREAM is involved in the genesis of proinflammatory and prolabour mediators induced by IL- $1 \beta$.

Activation of TLRs within intrauterine tissues is an important catalyst of preterm labour, with animal models identifying a role for TLR2 and TLR3 in particular. TLR2 ligation by bacterial products can induce preterm birth in 
mice, while, conversely, mice lacking TLR2 demonstrate reduced expression of inflammatory and contractile genes as well as delayed timing of labour $[49,50]$. There is also a synergy between TLR2 and TLR3, as combined stimulation using both agonists leads to induction of the inflammatory response and preterm labour in the mouse, caused by the alternate ligand [51]. In mice, advancing gestation is correlated with enhanced amniotic fluid expression of TLR2 and in humans TLR2 expression is increased in myometrium and fetal membranes in association with spontaneous term and preterm labour with evidence of chorioamnionitis [50, 52, 53]. Additionally, fsl-1, flagellin, and poly(I:C) (TLR2, TLR5, and TLR3 agonists, respectively) upregulate the expression and release of proinflammatory and prolabour mediators in myometrium and fetal membranes [21, 33, 41, 54]. DREAM has been shown to play an important role in regulating inflammation in response to infection. In a model of polymicrobial sepsis in DREAM-deficient mice, decreased IL-6, MCP-1, and ICAM-1 release was found in bronchoalveolar lavage fluid [24]. In support of these findings, our study demonstrates that siDREAM knockdown in primary myometrial cells associated with a significant decrease in fsl-1-, flagellin-, and poly(I:C)-induced expression and secretion of the proinflammatory cytokines IL-6, the chemokines IL- 8 and MCP-1, and the adhesion molecule ICAM-1. This suggests that DREAM plays an important role in TLR signalling pathways associated with preterm labour.

Recent studies have identified DREAM as a regulator of NF- $\kappa \mathrm{B}$, a proinflammatory transcription factor critical to the synthesis of prolabour mediators $[15,16]$. NF- $\kappa \mathrm{B}$ signalling components, including RelA, have been identified in numerous gestational cells and tissues, with labourassociated increases in NF- $\kappa \mathrm{B}$ signalling activity reported in myometrium, cervix, and amnion [55-58]. Decreased expression of multiple NF- $\kappa \mathrm{B}$ signalling components has been demonstrated in lung vascular endothelial cells and neutrophils from DREAM-deficient mice [24, 25]. In our study, siDREAM knockdown was associated with a significant decrease in IL-1 $\beta$-, fsl-1-, flagellin-, and poly(I:C)induced NF- $\kappa$ B RelA transcriptional activity. Altogether, these findings suggest that, in human myometrium, DREAM is a mediator of the NF- $\kappa \mathrm{B}$ signalling pathway, corroborating the potential of DREAM as a therapeutic target for the prevention of preterm labour.

Despite clinical interventions and extensive research, preterm birth rates continue to rise [59]. This may be due to an incomplete understanding of the mechanisms of human labour. This study suggests a role for DREAM in inflammation- and/or infection-induced preterm birth. DREAM mRNA expression is increased with preterm labour and in preterm amnion with histological chorioamnionitis, with loss-of-function studies suggesting that DREAM may regulate proinflammatory and prolabour mediators via NF$\kappa \mathrm{B}$ signalling in human myometrium and fetal membranes. Thus, inhibition of DREAM represents a novel therapeutic strategy for the prevention and management of preterm labour. Further studies are required to fully ascertain the role of DREAM in the processes of parturition.

\section{Conflicts of Interest}

The authors have no conflicts of interest to declare.

\section{Acknowledgments}

Associate Professor Martha Lappas is supported by a Career Development Fellowship from the National Health and Medical Research Council (NHMRC; Grant no. 1047025) and a Research Fellowship from The University of Melbourne. Funding for this study was provided by the NHMRC (Grant no. 1058786), Norman Beischer Medical Research Foundation, The University of Melbourne, and the Mercy Research Foundation. The clinical research midwives, Genevieve Christophers, Gabrielle Pell, and Rachel Murdoch, are gratefully acknowledged for their assistance with sample collection. The Obstetrics and Midwifery staff of Mercy Hospital for Women are acknowledged for their cooperation, and gratitude is extended to the women who so generously joined this study.

\section{References}

[1] L. Liu, H. Johnson, and S. Cousens, "Global, regional and national causes of child mortality: an update systematic analysis for 2010 with time trends since 2000," The Lancet, vol. 379, no. 9832, pp. 2151-2161, 2012.

[2] R. L. Goldenberg, J. F. Culhane, J. D. Iams, and R. Romero, "Epidemiology and causes of preterm birth," The Lancet, vol. 371, no. 9606, pp. 75-84, 2008.

[3] M. K. Mwaniki, M. Atieno, J. E. Lawn, and C. R. Newton, "Long-term neurodevelopmental outcomes after intrauterine and neonatal insults: a systematic review," The Lancet, vol. 379, no. 9814, pp. 445-452, 2012.

[4] S. Saigal and L. W. Doyle, "An overview of mortality and sequelae of preterm birth from infancy to adulthood," The Lancet, vol. 371, no. 9608, pp. 261-269, 2008.

[5] S. Petrou, O. Eddama, and L. Mangham, "A structured review of the recent literature on the economic consequences of preterm birth," ADC - Fetal and Neonatal Edition, vol. 96, no. 3, pp. F225F232, 2011.

[6] A. J. Thomson, J. F. Telfer, A. Young et al., "Leukocytes infiltrate the myometrium during human parturition: further evidence that labour is an inflammatory process," Human Reproduction, vol. 14, no. 1, pp. 229-236, 1999.

[7] I. Osman, A. Young, M. A. Ledingham et al., "Leukocyte density and pro-inflammatory cytokine expression in human fetal membranes, decidua, cervix and myometrium before and during labour at term," Molecular Human Reproduction, vol. 9, no. 1, pp. 41-45, 2003.

[8] R. Romero, M. Mazor, F. Brandt et al., "Interleukin- $1 \alpha$ and interleukin- $1 \beta$ in preterm and term human parturition," American Journal of Reproductive Immunology, vol. 27, no. 3-4, pp. 117-123, 1992.

[9] M. Nadeau-Vallée, D. Obari, C. Quiniou et al., "A critical role of interleukin-1 in preterm labor," Cytokine \& Growth Factor Reviews, vol. 28, pp. 37-51, 2016.

[10] J. K. Pollard and M. D. Mitchell, "Intrauterine infection and the effects of inflammatory mediators on prostaglandin production by myometrial cells from pregnant women," American Journal of Obstetrics \& Gynecology, vol. 174, no. 2, pp. 682-686, 1996. 
[11] S. R. Bartlett, R. Sawdy, and G. E. Mann, "Induction of cyclooxygenase-2 expression in human myometrial smooth muscle cells by interleukin-1 $\beta$ : Involvement of p38 mitogen-activated protein kinase," The Journal of Physiology, vol. 520, no. 2, pp. 399-406, 1999.

[12] D. Kumar, W. Fung, R. M. Moore et al., "Proinflammatory cytokines found in amniotic fluid induce collagen remodeling, apoptosis, and biophysical weakening of cultured human fetal membranes," Biology of Reproduction, vol. 74, no. 1, pp. 29-34, 2006.

[13] R. Romero, J. Espinoza, J. P. Kusanovic et al., "The preterm parturition syndrome," BJOG: An International Journal of Obstetrics \& Gynaecology, vol. 113, supplement 3, pp. 17-42, 2006.

[14] R. F. Lamont, "Infection in the prediction and antibiotics in the prevention of spontaneous preterm labour and preterm birth," BJOG: An International Journal of Obstetrics \& Gynaecology, vol. 110, no. 20, pp. 71-75, 2003.

[15] M. Lappas and G. E. Rice, "The Role and Regulation of the Nuclear Factor Kappa B Signalling Pathway in Human Labour," Placenta, vol. 28, no. 5-6, pp. 543-556, 2007.

[16] T. M. Lindström and P. R. Bennett, "The role of nuclear factor kappa B in human labour," Reproduction, vol. 130, no. 5, pp. 569581, 2005.

[17] V. C. Allport, D. Pieber, D. M. Slater, R. Newton, J. O. White, and P. R. Bennett, "Human labour is associated with nuclear factor$\kappa \mathrm{B}$ activity which mediates cyclo-oxygenase- 2 expression and is involved with the 'functional progesterone withdrawal,' Molecular Human Reproduction, vol. 7, no. 6, pp. 581-586, 2001.

[18] J. C. Condon, D. B. Hardy, K. Kovaric, and C. R. Mendelson, "Up-regulation of the progesterone receptor (PR)-C isoform in laboring myometrium by activation of nuclear factor- $\kappa \mathrm{B}$ may contribute to the onset of labor through inhibition of PR function," Molecular Endocrinology, vol. 20, no. 4, pp. 764-775, 2006.

[19] M. Lappas, M. Permezel, H. M. Georgiou, and G. E. Rice, "Nuclear factor Kappa B regulation of proinflammatory cytokines in human gestational tissues in vitro," Biology of Reproduction, vol. 67, no. 2, pp. 668-673, 2002.

[20] M. Lappas, M. Permezel, and G. E. Rice, "N-Acetyl-cysteine inhibits phospholipid metabolism, proinflammatory cytokine release, protease activity, and nuclear factor- $\kappa \mathrm{B}$ deoxyribonucleic acid-binding activity in human fetal membranes in Vitro," The Journal of Clinical Endocrinology \& Metabolism, vol. 88, no. 4, pp. 1723-1729, 2003.

[21] R. Lim, G. Barker, and M. Lappas, "TLR2, TLR3 and TLR5 regulation of pro-inflammatory and pro-labour mediators in human primary myometrial cells," Journal of Reproductive Immunology, vol. 122, pp. 28-36, 2017.

[22] G. Pirianov, S. N. Waddington, T. M. Lindström, V. Terzidou, H. Mehmet, and P. R. Bennett, "The cyclopentenone 15-deoxy- $\delta 12,14$-prostaglandin J 2 delays lipopolysaccharideinduced preterm delivery and reduces mortality in the newborn mouse," Endocrinology, vol. 150, no. 2, pp. 699-706, 2009.

[23] Y. Zhang, Y. Li, Y.-R. Yang, H.-H. Zhu, J.-S. Han, and Y. Wang, "Distribution of Downstream Regulatory Element Antagonist Modulator (DREAM) in rat spinal cord and upregulation of its expression during inflammatory pain," Neurochemical Research, vol. 32, no. 9, pp. 1592-1599, 2007.

[24] C. Tiruppathi, D. Soni, D.-M. Wang et al., "The transcription factor DREAM represses the deubiquitinase A20 and mediates inflammation," Nature Immunology, vol. 15, no. 3, pp. 239-247, 2014.
[25] A. Barazia, J. Li, K. Kim, C. Tiruppathi, and J. Cho, "Neutrophil DREAM Is a Novel Regulator for Beta2 Integrin Function through NF-Kappab Signaling and Modulates Neutrophil Recruitment during Vascular Inflammation," Blood, vol. 126, pp. 888-888, 2015.

[26] H.-N. Woo, J.-W. Chang, Y.-H. Choi, A.-R. Gwon, Y.-K. Jung, and D.-G. Jo, "Characterization of subcellular localization and Ca2+ modulation of calsenilin/DREAM/KChIP3," NeuroReport, vol. 19, no. 12, pp. 1193-1197, 2008.

[27] A. M. Carrión, W. A. Link, F. Ledo, B. Mellström, and J. R. Naranjo, "DREAM is a Ca2+-regulated transcriptional repressor," Nature, vol. 398, no. 6722, pp. 80-84, 1999.

[28] W. Frank An, M. R. Bowlby, M. Betty et al., "Modulation of Atype potassium channels by a family of calcium sensors," Nature, vol. 403, no. 6769, pp. 553-556, 2000.

[29] J. D. Buxbaum, E.-K. Choi, Y. Luo et al., "Calsenilin: A calciumbinding protein that interacts with the presenilins and regulates the levels of a presenilin fragment," Nature Medicine, vol. 4, no. 10, pp. 1177-1181, 1998.

[30] H.-Y. M. Cheng, G. M. Pitcher, S. R. Laviolette et al., "DREAM is a critical transcriptional repressor for pain modulation," Cell, vol. 108, no. 1, pp. 31-43, 2002.

[31] M. Savignac, B. Pintado, A. Gutierrez-Adan, M. Palczewska, B. Mellström, and J. R. Naranjo, "Transcriptional repressor DREAM regulates T-lymphocyte proliferation and cytokine gene expression," EMBO Journal, vol. 24, no. 20, pp. 3555-3564, 2005.

[32] D. Baczyk, M. Kibschull, B. Mellstrom et al., "DREAM Mediated Regulation of GCM1 in the Human Placental Trophoblast," PLoS ONE, vol. 8, no. 1, Article ID e51837, 2013.

[33] M. Hoang, J. A. Potter, S. M. Gysler et al., "Human fetal membranes generate distinct cytokine profiles in response to bacterial toll-like receptor and nod-like receptor agonists," Biology of Reproduction, vol. 90, no. 2, Article ID Article 39, 2014.

[34] M. Lappas, “The IL-1 $\beta$ signalling pathway and its role in regulating pro-inflammatory and pro-labour mediators in human primary myometrial cells," Reproductive Biology, 2017.

[35] R. Lim, G. Barker, and M. Lappas, "Inhibition of PIMI kinase attenuates inflammation-induced pro-labour mediators in human foetal membranes in vitro," Molecular Human Reproduction, vol. 23, no. 6, Article ID gax013, pp. 428-440, 2017.

[36] A. T. N. Tita and W. W. Andrews, "Diagnosis and management of clinical chorioamnionitis," Clinics in Perinatology, vol. 37, no. 2, pp. 339-354, 2010.

[37] M. Lappas, A. Mitton, R. Lim, G. Barker, C. Riley, and M. Permezel, "SIRT1 is a novel regulator of key pathways of human labor," Biology of Reproduction, vol. 84, no. 1, pp. 167-178, 2011.

[38] R. Lim, G. Barker, C. A. Wall, and M. Lappas, "Dietary phytophenols curcumin, naringenin and apigenin reduce infectioninduced inflammatory and contractile pathways in human placenta, foetal membranes and myometrium," Molecular Human Reproduction, vol. 19, no. 7, pp. 451-462, 2013.

[39] R. Lim, G. Barker, and M. Lappas, “TREM-1 expression is increased in human placentas from severe early-onset preeclamptic pregnancies where it may be involved in syncytialization," Reproductive Sciences, vol. 21, no. 5, pp. 562-572, 2014.

[40] R. Lim, H. T. Tran, S. Liong, G. Barker, and M. Lappas, "The transcription factor interferon regulatory factor-1 (IRF1) plays a key role in the terminal effector pathways of human preterm labor," Biology of Reproduction, vol. 94, no. 2, article no. 32, 2016. 
[41] R. Lim, G. Barker, and M. Lappas, “The TLR2 ligand FSL-1 and the TLR5 ligand flagellin mediate pro-inflammatory and prolabour response via MyD88/TRAF6/NF- $\kappa$ B-dependent signalling," American Journal of Reproductive Immunology, vol. 71, no. 5, pp. 401-417, 2014.

[42] J. A. Keelan, M. Blumenstein, R. J. A. Helliwell, T. A. Sato, K. W. Marvin, and M. D. Mitchell, "Cytokines, prostaglandins and parturition - A review," Placenta, vol. 24, pp. S33-S46, 2003.

[43] R. Romero, M. Mazor, and B. Tartakovsky, "Systemic administration of interleukin-1 induces preterm parturition in mice," American Journal of Obstetrics \& Gynecology, vol. 165, no. 4, pp. 969-971, 1991.

[44] D. W. Sadowsky, K. M. Adams, M. G. Gravett, S. S. Witkin, and M. J. Novy, "Preterm labor is induced by intraamniotic infusions of interleukin- $1 \beta$ and tumor necrosis factor- $\alpha$ but not by interleukin- 6 or interleukin- 8 in a nonhuman primate model," American Journal of Obstetrics \& Gynecology, vol. 195, no. 6, pp. 1578-1589, 2006.

[45] C.-R. Roh, W.-J. Oh, B.-K. Yoon, and J.-H. Lee, “Up-regulation of matrix metalloproteinase-9 in human myometrium during labour: A cytokine-mediated process in uterine smooth muscle cells," Molecular Human Reproduction, vol. 6, no. 1, pp. 96-102, 2000 .

[46] M. Tattersall, N. Engineer, S. Khanjani et al., "Pro-labour myometrial gene expression: Are preterm labour and term labour the same?" Reproduction, vol. 135, no. 4, pp. 569-579, 2008.

[47] G. Chevillard, A. Derjuga, D. Devost, H. H. Zingg, and V. Blank, "Identification of interleukin- $1 \beta$ regulated genes in uterine smooth muscle cells," Reproduction, vol. 134, no. 6, pp. 811-822, 2007.

[48] R. Lim, G. Barker, and M. Lappas, "SMAD7 regulates proinflammatory and prolabor mediators in amnion and myometrium," Biology of Reproduction, vol. 97, no. 2, pp. 288-301, 2017.

[49] A. P. Montalbano, S. Hawgood, and C. R. Mendelson, "Mice deficient in surfactant protein A (SP-A) and SP-D or in TLR2 manifest delayed parturition and decreased expression of inflammatory and contractile genes," Endocrinology, vol. 154, no. 1, pp. 483-498, 2013.

[50] V. Ilievski, S.-J. Lu, and E. Hirsch, "Activation of toll-like receptors 2 or 3 and preterm delivery in the mouse," Reproductive Sciences, vol. 14, no. 4, pp. 315-320, 2007.

[51] V. Ilievski and E. Hirsch, "Synergy between viral and bacterial toll-like receptors leads to amplification of inflammatory responses and preterm labor in the mouse," Biology of Reproduction, vol. 83, no. 5, pp. 767-773, 2010.

[52] M. O'Brien, J. J. Morrison, and T. J. Smith, "Upregulation of PSCDBP, TLR2, TWIST1, FLJ35382, EDNRB, and RGS12 gene expression in human myometrium at labor," Reproductive Sciences, vol. 15, no. 4, pp. 382-393, 2008.

[53] Y. M. Kim, R. Romero, T. Chaiworapongsa et al., "Tolllike receptor-2 and -4 in the chorioamniotic membranes in spontaneous labor at term and in preterm parturition that are associated with chorioamnionitis," American Journal of Obstetrics \& Gynecology, vol. 191, no. 4, pp. 1346-1355, 2004.

[54] H. Moroi, T. Kotani, R. Miki et al., "The expression of Toll-like receptor 5 in preterm histologic chorioamnionitis," Journal of Clinical Biochemistry and Nutrition, pp. 1-5, 2017.

[55] A. R. Belt, J. J. Baldassare, M. Molnár, R. Romero, and F. Hertelendy, "The nuclear transcription factor NF- $\kappa \mathrm{B}$ mediates interleukin-1 $\beta$-induced expression of cyclooxygenase- 2 in human myometrial cells," American Journal of Obstetrics \& Gynecology, vol. 181, no. 2, pp. 359-366, 1999.

[56] N. R. Chapman, G. N. Europe-Finner, and S. C. Robson, "Expression and deoxyribonucleic acid-binding activity of the nuclear factor $\kappa \mathrm{B}$ family in the human myometrium during pregnancy and labor," The Journal of Clinical Endocrinology \& Metabolism, vol. 89, no. 11, pp. 5683-5693, 2004.

[57] T. M. Lindström and P. R. Bennett, "15-Deoxy- $\delta 12,14$ prostaglandin $\mathrm{J} 2$ inhibits interleukin- $1 \beta$-induced nuclear factor- $\kappa \mathrm{B}$ in human amnion and myometrial cells: Mechanisms and implications," The Journal of Clinical Endocrinology \& Metabolism, vol. 90, no. 6, pp. 3534-3543, 2005.

[58] S. J. Choi, S. Y. Oh, J. H. Kim, and C. R. Roh, "Changes of nuclear factor kappa B (NF- $\kappa \mathrm{B})$, cyclooxygenase-2 (COX-2) and matrix metalloproteinase-9 (MMP-9) in human myometrium before and during term labor," European Journal of Obstetrics \& Gynecology and Reproductive Biology, vol. 132, no. 2, pp. 182188, 2007.

[59] J. D. Lantos and D. S. Lauderdale, "What is Behind the Rising Rates of Preterm Birth in the United States?" Rambam Maimonides Medical Journal, vol. 2, no. 4, p. e0065, 2011. 


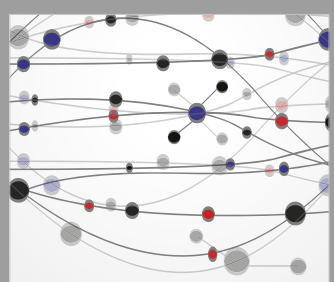

The Scientific World Journal
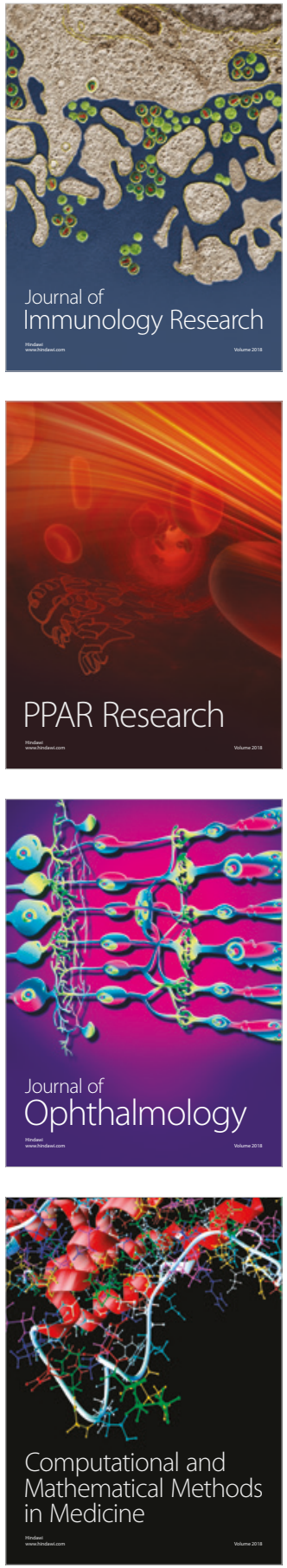

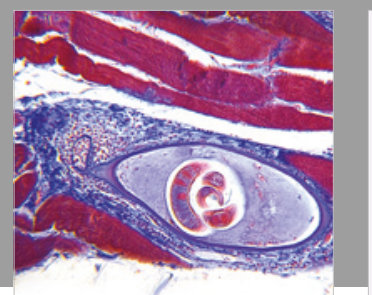

Gastroenterology Research and Practice

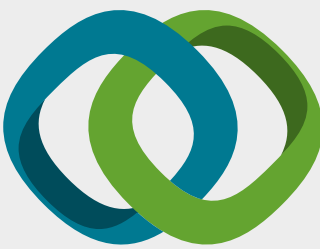

\section{Hindawi}

Submit your manuscripts at

www.hindawi.com
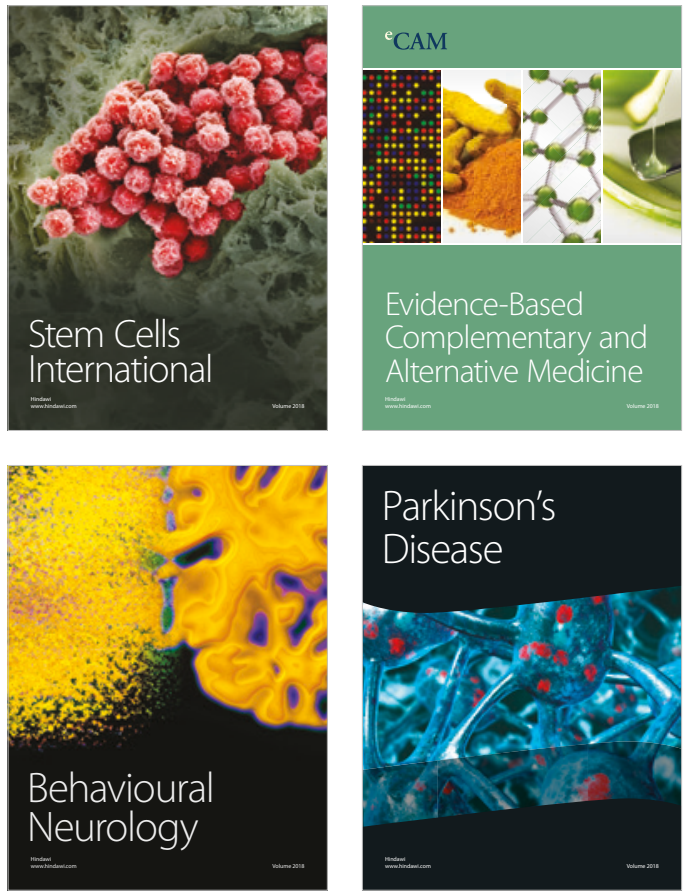

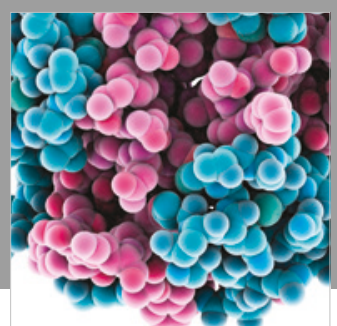

ournal of

Diabetes Research

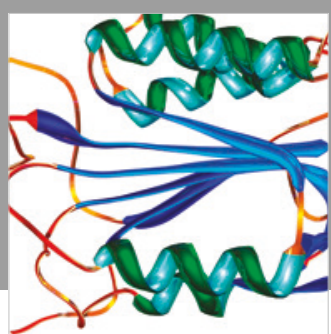

Disease Markers
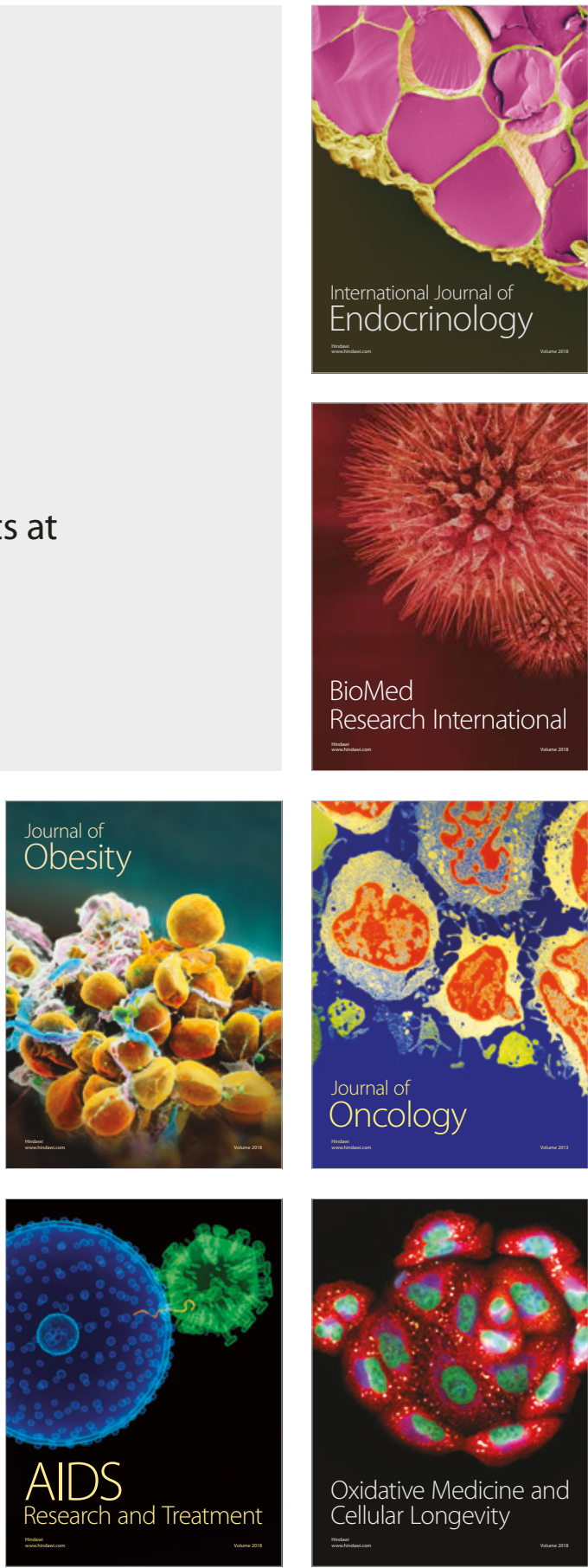